\title{
Is there a future for restricted elimination diets in ADHD clinical practice?
}

\author{
Nanda Rommelse $\cdot$ Jan Buitelaar
}

Published online: 27 February 2013

(C) Springer-Verlag Berlin Heidelberg 2013

Attention deficit hyperactivity disorder (ADHD) is a neuropsychiatric disorder characterized by symptoms of inattention, impulsive behavior and hyperactivity [1]. The disorder affects about $5 \%$ of all children and adolescents [2], and generally manifests itself before the age of seven years. Children and adolescents with ADHD often have other psychiatric and developmental problems such as oppositional defiant disorder (ODD), conduct disorder (CD), autism spectrum disorder (ASD), specific learning disorders like dyslexia and dyscalculia, developmental motor coordination disorder (DCD), and anxiety and mood disorders. Though ADHD is classified as a childhood disorder, a large proportion of individuals will continue to exhibit symptoms into adolescence and adulthood [3]. This places them at high risk of social and economic disadvantage in the course of the lifespan and puts a large strain on social and healthcare services.

Studies in twins and adopted children indicate that genetic factors play an important role in the etiology of ADHD [4]. However, the role of environmental factors contributing to childrens' vulnerability to develop ADHD should not be ignored [5]. One of the relevant environmental factors seems to be food. There is a growing awareness that food may play a role in determining not only our physical well-being, but also our behaviour and cognitive functioning [6-8]. The role of food in ADHD has been investigated since 1985 in several restricted elimination diet (RED) studies. A restricted elimination diet is commonly used to identify food intolerance and involves a temporary (2-5 weeks) total change of diet, in which the patient is only allowed to eat a few different hypo-

N. Rommelse $(\bowtie) \cdot$ J. Buitelaar

Nijmegen, Netherlands

e-mail: N.Lambregts-Rommelse@psy.umcn.nl allergenic foods (including rice, turkey, lettuce, pears, and water) [9-17]. The rationale for this diet is that a patient may show adverse reactions to any foods. Although various forms of restricted elimination diets have been designed and applied in ADHD patients, and modest to substantial behavioural improvements have been observed. Further research into the relationship between food and behaviour is therefore recommended by the National Institutes of Health in the USA [18].

In the Netherlands, three randomized controlled trials (RCTs) have been conducted over the last 10 years [13-15]. The elimination diet applied in these studies is based on the few foods diet, but is somewhat more extensive: rice, turkey, lamb, a range of vegetables, pear, rice milk with added calcium and water. This basis is complemented with potatoes, fruits, corn, some sweets and wheat, allowed in limited doses twice a week. Vegetables, fruits, rice and meat are allowed every day, in normal doses. Occasionally, the diet will be varied to avoid foods for which the child has a particular craving or dislike. The first phase (elimination phase) covers 5 weeks, the second phase (reintroduction phase) may last up to 1.5 years and only includes children who respond to the first phase with a significant $(40 \%)$ reduction in ADHD symptoms. During the reintroduction phase, parents see a dietician every $1-2$ weeks to identify foods that trigger ADHD symptoms in their child. Eventually this phase leads to a consolidated dietary advice about the specific foods to be avoided. On average, this concerns three to five foods. These studies showed that this elimination diet may be effective in about $60 \%$ of the children and may also significantly reduce comorbid oppositional defiant disorder symptoms as well as physical complaints, such as abdominal pain, diarrhoea, headaches, eczema, or asthma.

The latest conducted Dutch RCT applying a RED was published in The Lancet [15] and was both applauded as 
well as criticized in scientific and public media [19-21]. It is thus far the largest study conducted of this kind, in ADHD patients not selected for an atopic constitution or presence/absence of comorbidities, and with a rigorous attempt to investigate possible immunological mechanisms underlying response to RED. Results indicated that $64 \%$ of the children responded with at least $40 \%$ ADHD symptom reduction in the first phase of the diet according to both pediatrician/parent and teacher ratings. A large effect on ODD symptom reduction was found as well. The diet-responders continued with a 4-week challenge phase, in which, from a list of 270 different foods, randomly during 2 weeks three foods were added to which the participant showed high IgG blood levels at baseline and during the other 2 weeks three foods to which the participant showed low IgG blood levels. Over $60 \%$ of the children showed a behavioral relapse during this challenge phase, which was not specifically related to high or low IgG foods.

The main point of criticism raised regarding the study is the unsatisfactory blinding, with primary outcome measurements based on a blinded pediatrician's clinical judgement, who based his judgement on the non-blinded information provided to him by parents. Expectation bias originating from parents and/or pediatrician may have potentially influenced the outcomes. A second point of criticism was the nature of the control group, receiving non-obligatory healthy food advice. It cannot be ruled out for certain that non-dietary factors, such as increased (positive) attention towards the child and/or increased structure in the household, may have contributed to the positive outcomes in the dietary group, although no change in family structure was observed in these already highly organized households [22].

In addition, some other issues are still open and need to be resolved before more final conclusions can be drawn on the utility and place of RED in treatment guidelines of ADHD. Among these is the unknown long-term effectiveness of RED, i.e. are treatment effects maintained over time, and how many children do have a consolidated diet from which the incriminated foods only are eliminated, 2 years after startying with RED? Further, what is the effectivness and cost-effectiveness of dietary interventions compared to care as usual (CAU)? Next, how effective and feasible is RED when it is administered by health care professionals working in clinical practice rather than by a single private ADHD research center? How effective and feasible is the long and burdensome reintroduction phase of RED when offered to "normal" unselective ADHD families that were not a priori highly motivated for diet interventions? In other words, can the results of RED be generalized to the more broader population of ADHD patients? Finally, what are the effects of RED on childrens' self-esteem and social status? Do they feel stigmatized and isolated since they have to obey strict rules and regulations about diet habits that will likely differ from those observed by their peers? A recent meta-analysis excluded the Dutch studies because the effect sizes were significanty larger than the other studies of this kind [21]. Excluding outliers in meta-analyses is not generally considered to be the standard approach as outliers may actually "reveal patterns that may lead to new insights about study characteristics that could be acting as potential moderators, i.e. characteristics of treatment" [23]. However, despite the limitations of the study, a substantial percentage of children improved significantly according to multiple raters. It is unlikely that only expectation bias can explain such drastic behavioral improvements in so many children. If so, this is perhaps the largest and most dramatic placebo-effect documented thus far in ADHD research and it is certainly worthwhile pursuing this matter further.

Nevertheless, the raised critique should be taken very seriously, since it is both valid as well as indicative of reluctance in scientific and public circles to move forward with applying dietary interventions in clinical practice. We would recommend to follow-up on the promising results, trying to incorporate the critique into a better designed study that is more able to convince criticasters than the existing studies. Therefore, we would like to make the following specific recommendations for future studies examining the effects of dietary interventions in ADHD. A longitudinal (at least 2 years) three-armed RCT including a restricted elimination diet and two control arms, CAU and a control diet, is perhaps most optimal in addressing the criticism regarding non-dietary factors explaining the reduction of symptoms in the elimination diet arm. The control diet can be a normal diet, satisfying the World Health Organization Guidelines for a healthy diet, but offered in a strict manner. In this way, it will affect the household, the (positive) attention that the child receives and the structure to their daily diet as the elimination diet does, without affecting the allergen content of the diet. Importantly, parents and child must have the expectancy that both diets will be equally effective. Even if this control diet is offered for only 6 months, it is a useful control as to whether prescribing a strict diet is the most powerful and effective behavioural intervention in ADHD. Furthermore, comparison with CAU will allow to examine the effectiveness and cost-effectiveness compared to treatments currently available for ADHD (medication and behavioural therapy). Measurements should include not only parental and teacher ADHD rating scales, but also observations made by a blinded clinician and preferably objective cognitive and motor-activity (i.e. actigraph) measures and when feasible, blood, urine and bowel samples. The latter might point into the direction of possible biological 
working mechanisms underlying the effect of RED. If possible, the study should be carried out in health care centers that are independent from the private ADHD research center and include all new referrals to examine generalizability of the findings. Information regarding number and characteristics of drop-outs are highly relevant before implementation of dietary interventions for ADHD in clinical practice can occur. In addition, every effort should be made to find a method to lighten the reintroduction phase and thus alleviate the burden of the second phase of dietary research for the child and family members.

But why go through all this trouble when CAU (mainly psychoeducation, medication and/or behaviour therapy) offers significant benefits to about $80 \%$ of patients, such as substantial reduction of symptoms and better psychosocial adaptation and functioning? The main reason for doing so is that there is growing concern among parents, health care professionals and politicians about overprescription of medication, particularly psychostimulants, and about potential longterm side-effects [24]. In addition, there is no conclusive evidence that any of these treatments improve the longterm prognosis [25]. There is a demand for dietary interventions as an alternative treatment for ADHD, illustrated by the fact that on average children wait 6 months before they can start with an elimination diet diagnostic trajectory at one of the four private ADHD research centers in The Netherlands, despite the fact that it is not reimbursed. Furthermore, the RED intervention, eliminating the trigger for ADHD symptoms, may be a very cost-effective approach since treatment expenses are almost limited to once-only costs for a complete diagnostic trajectory. In contrast, CAU, and especially the use of methylphenidate, will pose continuous burdens on the public health care. Nation-wide implementability of RED is probably feasible, given that RED is widely used to identify food intolerance. Therefore, dieticians in cooperation with child psychiatrists, psychologists and/or pediatricians can administer RED intervention for ADHD relatively easily nation-wide. If proven long-term (cost-) effective, RED may provide an alternative treatment, which is likely to be recommended in guidelines for ADHD treatment and is likely to qualify for reimbursement under public health insurance. So yes, we believe there is a future for dietary interventions in ADHD clinical practice, but valid and important points of criticism should be tackled first before implementation in clinical practice can be considered.

\section{References}

1. American Psychiatric Association (2000) Diagnostic and statistical manual of disorders. Text revision, 4th edn. American Psychiatric Association, Washington DC
2. Polanczyk G, de Lima MS, Horta BL, Biederman J, Rohde LA (2007) The worldwide prevalence of ADHD: a systematic review and metaregression analysis. Am J Psychiatry 164:942-948

3. Faraone SV, Biederman J, Mick E (2006) The age-dependent decline of attention deficit hyperactivity disorder: a meta-analysis of follow-up studies. Psychol Med 36:159-165

4. Nikolas MA, Burt SA (2010) Genetic and environmental influences on ADHD symptom dimensions of inattention and hyperactivity: a meta-analysis. J Abnorm Psychol 119:1-17

5. Wood AC, Buitelaar J, Rijsdijk F, Asherson P, Kuntsi J (2010) Rethinking shared environment as a source of variance underlying attention-deficit/hyperactivity disorder symptoms: comment on Burt (2009). Psychol Bull 136:331-340

6. Blanchflower DG, Oswald AJ, Stewart-Brown S (2012) Is psychological well-being linked to the consumption of fruit and vegetables? NBER Working Paper No.18469. doi:10.1007/ s11205-012-0173-y

7. Durga J, van Boxtel MPJ, Schouten EG, Kok FJ, Jolles J, Katan MB, Verhoef P (2007) Effect of 3-year folic acid supplementation on cognitive function in older adults in the FACIT trial: a randomised, double blind, controlled trial. Lancet 369:208-216

8. Warsama Jama J, Launer LJ, Witteman JCM, den Breeijen JH, Breteler MMB, Grobbee DE, Hofman A (1996) Dietary antioxidants and cognitive function in a population-based sample of older persons. The Rotterdam study. Am J Epidemiol 144:275-280

9. Boris M, Mandel FS (1994) Food and additives are common causes of the attention deficit hyperactive disorder in children. Ann Allergy 72:462-468

10. Carter CM, Urbanowicz M, Hemsley R, Mantilla L, Strobel S, Graham PJ, Taylor E (1993) Effects of a few food diet in attention deficit disorder. Arch Dis Child 69:564-568

11. Egger J, Carter CM, Graham PJ, Gumley D, Soothill JF (1985) Controlled trial of oligo-antigenic treatment in the hyperkinetic syndrome. Lancet 1:540-545

12. Kaplan BJ, McNicol J, Conte RA, Moghadam HK (1989) Dietary replacement in preschool-aged hyperactive boys. Pediatrics 83:7-17

13. Pelsser LMJ (2003) De invloed van voeding op hyperactief gedrag bij kinderen met ADHD. Kind En Adolescent 1:4-16

14. Pelsser LMJ, Buitelaar JK (2002) Gunstige invloed van een standaardeliminatiedieet op het gedrag van jonge kinderen met aandachtstekort-hyperactiviteitsstoornis (ADHD): een verkennend onderzoek. Ned Tijdschr Geneesk 146:2543-2547

15. Pelsser LM, Frankena K, Toorman J, Savelkoul HF, Dubois AE, Pereira RR et al (2011) Effects of a restricted elimination diet on the behaviour of children with attention-deficit hyperactivity disorder (INCA study): a randomised controlled trial. Lancet 377:494-503

16. Schulte-Korne G, Deimel W, Gutenbrunner C, Hennighausen K, Blank R, Rieger C, Remschmidt H (1996) Effect of an oligoantigen diet on the behavior of hyperkinetic children. Z Kinder Jugendpsychiatr Psychother 24:176-183

17. Schmidt MH, Mocks P, Lay B, Eisert HG, Fojkar R, Fritz-Sigmund D et al (1997) Does oligoantigenic diet influence hyperactive/conduct-disordered children, a controlled trial. Eur Child Adolesc Psychiatry 6:88-95

18. National Institutes of Health Consensus Development Conference Statement (2000) Diagnosis and treatment of attention-deficit/ hyperactivity disorder (ADHD)). J Am Acad Child Adolesc Psychiatry 39:182-193

19. Ghuman JK (2011) Comment. Restricted elimination diet for ADHD: the INCA study. Lancet 377:446-448

20. RIVM. Voeding en ADHD: beoordeling van de INCA-studie. Briefrapport 350021002. 3 october 2011

21. Sonuga-Barke EJS, Brandeis D, Cortese S, Daley D, Ferrin M, Holtmann $\mathrm{M}$ et al (2013) Nonpharmacological interventions for 
ADHD: systematic review and meta-analyses of randomized controlled trials of dietary and psychological treatments. Am J Psychiatry (epub ahead of print)

22. Pelsser LM, van Steijn DJ, Frankena K, Toorman J, Buitelaar JK, Rommelse NN (2012) A randomized controlled pilot study into the effects of a restricted elimination diet on family structure in families with ADHD and ODD. Child Adolesc Ment Health $18: 39-45$

23. Viechtbauer W, Cheung MWL (2010) Outlier and influence diagnostics for meta-analysis. Res Synth Meth 1:112-125
24. Graham J, Banaschewski T, Buitelaar J, Coghill D, Danckaerts M, Dittmann RW et al (2011) European guidelines on managing adverse effects of medication for ADHD. Eur Child Adolesc Psychiatry 20:17-37

25. van de Loo-Neus GHH, Rommelse N, Buitelaar JK (2011) To stop or not to stop? How long should medication treatment of attention-deficit hyperactivity disorder be extended? Eur Neuropsychopharmacol 21:584-599 